\title{
Risk factors for early interruption of exclusive breastfeeding and late introduction of complementary foods among infants in midwestern Brazil
}

\author{
Gisela S. Brunken, ${ }^{1}$ Solanyara M. Silva, ${ }^{2}$ Giovanny V. A. França, ${ }^{3}$ \\ Maria M. Escuder, 4 Sonia I. Venâncio 5
}

\begin{abstract}
Objective: To identify factors associated with early interruption (before 4 months) of exclusive breastfeeding and late introduction (after 8 months) of complementary foods.

Methods: This is a cross-sectional study, based on a survey conducted on the first day of the National Vaccination Campaign in 2004, in Cuiabá, MT, Brazil. The sample comprised 921 children less than 1 year old, and the adult accompanying each child was interviewed and a semi-structured questionnaire filled out. Probit analysis was employed to assess consumption of liquids and solids, and logistic regression analysis was applied to identify factors associated with early introduction of liquids and with late introduction of solids.

Results: There was elevated consumption of water and teas, followed by cow's milk among those less than 120 days old. Children were more likely to be being given liquids on the day of the survey if they had been consuming them on the day they were discharged from the maternity unit. Approximately $60 \%$ of the children were being given soup or the family meal by 8 months.

Conclusions: Liquids being given on the first day at home was a good predictor that they would be given for the first 4 months, emphasizing the need for intervention during prenatal care and at maternity units to counter the harm caused by this practice. After 8 months, however, it is necessary to emphasize the importance of the child participating in family meals, especially for adult mothers without higher education and primaparous mothers.
\end{abstract}

J Pediatr (Rio J). 2006;82(6):445-51: Weaning, complementary feeding, nutritional surveys, breastfeeding, infant nutrition.

\section{Introduction}

Since the 1970s, a great deal of research has been undertaken and many advances have been achieved in relation to the promotion of breastfeeding, but, unfortunately, complementary feeding has not been

1. Doutora em Nutrição Humana Aplicada. Professora, Instituto de Saúde Coletiva, Universidade Federal de Mato Grosso (UFMT), Cuiabá, MT, Brasil.

2. Mestre em Saúde Coletiva. Nutricionista, Secretaria Estadual de Saúde de Mato Grosso, Cuiabá, MT, Brasil.

3. Bolsista, Programa Institucional de Bolsas de Iniciação Científica (PIBIC). Estudante de Nutrição, UFMT, Cuiabá, MT, Brasil.

4. Mestre em Epidemiologia e Estatística, Instituto de Saúde, Secretaria Estadual de Saúde de São Paulo, São Paulo, SP, Brasil.

5. Doutora em Nutrição e Saúde Pública, Instituto de Saúde, Secretaria Estadual de Saúde de São Paulo, São Paulo, SP, Brasil.

Partial financial support: CAPES, CNPq (PIBIC), Secretarias Municipal e Estadual de Saúde de Mato Grosso, Brasil.

Manuscript received Dec 27 2005, accepted for publication Aug 072006

Suggested citation: Brunken GS, Silva SM, França GV, Escuder MM, Venâncio SI. Risk factors for early interruption of exclusive breastfeeding and late introduction of complementary foods among infants in midw estern Brazil. J Pediatr (Rio J). 2006;82:445-51. explored a great deal. In fact, opportune introduction of other foods after 6 months is just as important as the correct practice of exclusive breastfeeding up to 6 months. With this in mind, the Brazilian Health Ministry has produced a "Guide to Feeding Children Under Two Years Old"1 and Monte \& Giugliani ${ }^{2}$ have published recommendations for the complementary feeding of breastfed children. Both emphasize that complementary feeding is an essential factor for food security and for development of populations and their countries, with healthcare professionals being responsible for providing mothers with appropriate recommendations.

Exclusive breastfeeding for the first 6 months of life is a practice that is indispensable to the health and development of children. ${ }^{3}$ In Rio Grande do Sul state, children under 1 year who were not breastfed exhibited 14 times greater risk of death from diarrhea, and almost four times greater of death from respiratory diseases, when compared children of the same age fed exclusively 
at the breast. ${ }^{4}$ In addition to increased risk of infections, it is known that the administration of other foods in addition to breastmilk impacts negatively on nutrient absorption and bioavailability and can result in reduced quantities of breastmilk being consumed, leading to reduced weight gain. 5

However, after 6 months breastmilk may no longer be sufficient to provide children with their nutritional requirements, with complementary foods needed to fill this lack, especially of energy and iron. ${ }^{1}$

There are many benefits from introducing complementary feeding at the opportune moment, which, ideally, should not be before 6 months, since there are no benefits from introducing these foods early, and there may be adverse effects. ${ }^{3}$ Foods should be begun at 6 months, initially soft, pasty foods, known as transition foods, with progressive increase in consistency until the child is eating family meals, which should occur from 8 months onwards. ${ }^{1}$

This study aimed to identify factors associated with early interruption (before 4 months) of exclusive breastfeeding and late introduction (after 8 months) of complementary foods.

\section{Methods}

This is an analytical cross-sectional study, undertaken in June of 2004, in the municipality of Cuiabá, MT. A survey was made of dietary practices on the first day of the National Vaccination Campaign in 2004, as part of a partnership between the São Paulo State Health Department's Instituto de Saúde (Secretaria Estadual de Saúde), through their "Breastfeeding and Municipalities" project, and the Universidade Federal de Mato Grosso.

Data from the $1991^{6}$ and 2000 national censuses, ${ }^{7}$ were used to estimated a projected number of children less than 1 year old in Cuiabá for 2004 of 8,129. The planned sample size was 1,040 children, which, with a $10 \%$ safety margin, was sufficient to estimate the prevalence of breastfeeding at different ages to a $5 \%$ significance level.

A two-stage cluster sampling procedure was adopted. In the first stage Vaccination Centers were selected by lots, and, in the second, children were chosen systematically from each center. The aim was to obtain a sample with balanced probability, so that larger vaccination centers had a greater chance of being drawn in the first stage, and children from smaller centers a greater chance of being selected in the second.

The selection of 29 centers and the number of children whose mothers would be approached at each center were defined based on the total of 66 vaccination centers from the previous year. The randomization procedures were executed by the fieldwork supervisor and the interview team. On campaign "D-Day" (5th of June, 2004) 7,300 children presented at vaccination centers. Of these, 921 were selected for the sample.

The research instrument employed was developed by the Instituto de Saúde de São Paulo, based on World Health Organization recommendations for breastfeeding surveys. ${ }^{8}$ It was a semi-structured questionnaire, laid out in sections, containing variables related to the child's feeding, the birth (hospital and type of delivery), liquids given (water, tea or other types of milk) on the first day at home from hospital (for children under 120 days) and maternal characteristics. The section on feeding included questions on consumption of breastmilk, other types of milk, preparations such as "porridge, " "mashes" or "purées" (pasty meals prepared with some type of flour and/or fruit mixed with water or milk), "soups" (liquid or pasty savory meal, prepared especially for the child), "the family meal" (refers to food prepared for the whole family, which may have been mashed, shredded, chopped into small pieces, etc. ), meat or beans in soup or the family meal, water, tea and fruit during the previous 24 hours. When children had been brought for vaccination by their mothers, they were asked questions about their age, primiparity, education and employment away from home, in addition to the sections above.

Complementary food was defined according to the $\mathrm{WHO}^{8}$ and the Health Ministry Guide, ${ }^{1}$ also cited by Monte \& Giugliani ${ }^{2}$ as "any food other than breastmilk given in the complementary feeding period." The terms used in this article to refer to infant feeding are those currently recommended by the World Health Organization ${ }^{8}$ and adopted internationally.

The questionnaires were applied by students studying Nutrition, Nursing and Medicine and who had received training in data collection. An "Interviewer's Manual" was produced in order to standardize conduct in the field.

Adults accompanying children who were potential candidates for the sample were approached while waiting in line for vaccination and, once they had been informed of the research objectives and if they gave consent, were interviewed.

Data were double input using an ACCESS application called AMAMUNIC, which checks for consistency during data entry in addition to generating breastfeeding indicators. Once complete the twin databases were compared, using the Validate function in Epi-Info version $6.04 d$, and discrepancies were corrected.

\section{Plan of analysis}

Probit analysis was employed to estimate the probability that any given food would be introduced and its period of introduction, in order to identify those consumed with 
greater frequency before 4 months and those foods that families were consuming, but not giving to children older than 8 months. Probit analysis ${ }^{9}$ estimates the proportion of children who will exhibit this behavior by means of weighted linear regression of probits $(y)$ against age $(x)$, using the maximum likelihood iterative procedure.

Univariate analyses were then performed, taking consumption of each food of interest in turn as the dependent variable and the reasons for this consumption as independent variables. For children younger than 120 days, the foods investigated were water, tea and other types of milk and, for those older than 240 days, they were soup, the family meal, meat and beans. The independent variables investigated for children under 120 days were: consumption of liquids on the first day at home, socioeconomic variables and maternal characteristics; for those older than 240 days these were: maternal characteristics and socioeconomic variables.

Logistic regression was used for the multivariate analysis model, which included all variables whose significance level had been below 20\% ( $p<0.20)$ for the outcomes under univariate analysis. The stepwise forward selection method was used, with variables retained in the model only if they had $\mathrm{p}<0.05$.

The impact of the sample design on the variances of logistic regression estimates was captured in the form of design effect, using the CSAMPLE module in Epi-Info $6.04 \mathrm{~d}$, which gives the ratio between variance calculated assuming a complex sample and variance assuming a simple random sample. It was found that the design effect for any given estimator was always close to one, and it was possible to conclude that the sampling plan did not have any effect on the test of significance for the coefficient associated with the variable in question, indicating that variance could be acceptably calculated assuming a simple sample.

This Project was approved by the Research Ethics Committee at the Hospital Universitário Julio Muller, in Cuiabá, MT.

\section{Results}

The sample comprised 921 children, the majority of whom had been brought by their mothers (Table 1 ). Considering maternal characteristics; $1 / 6$ were younger than 20 years, one quarter had employment outside of the home and few had attended higher education, whether graduated or incomplete.

The sample studied was in equilibrium in terms of sex and distribution across age groups. Almost all of them were born in Cuiabá, with weight greater than or equal to $2,500 \mathrm{~g}$ and, less than half were delivered vaginally.
Table 1 - Characteristics of children and mothers (Cuiabá, MT, Brazil, 2004)

\begin{tabular}{|c|c|c|}
\hline Characteristics & $\mathbf{n}$ & $\%$ \\
\hline \multicolumn{3}{|l|}{ Infants } \\
\hline \multicolumn{3}{|l|}{ Sex } \\
\hline Male & 478 & 51.9 \\
\hline Female & 443 & 48.1 \\
\hline \multicolumn{3}{|l|}{ Age (days) } \\
\hline $0 \mid-120$ & 295 & 32.0 \\
\hline $120 \mid-240$ & 293 & 31.8 \\
\hline $240 \mid-365$ & 333 & 36.2 \\
\hline \multicolumn{3}{|l|}{ Birth weight (g) } \\
\hline$<2,500$ & 55 & 6.1 \\
\hline $2,500 \mid-3,000$ & 205 & 22.7 \\
\hline$\geq 3,000$ & 644 & 71.2 \\
\hline \multicolumn{3}{|l|}{ Place of birth } \\
\hline Cuiabá & 863 & 93.7 \\
\hline Other municipality & 58 & 6.3 \\
\hline \multicolumn{3}{|l|}{ Maternal } \\
\hline \multicolumn{3}{|c|}{ Mother brought own child? } \\
\hline Yes & 773 & 83.9 \\
\hline No & 148 & 16.1 \\
\hline \multicolumn{3}{|l|}{ Maternal age (years) } \\
\hline$<20$ & 127 & 16.4 \\
\hline$\geq 20$ & 646 & 83.6 \\
\hline \multicolumn{3}{|c|}{$\begin{array}{l}\text { Highest level of education attended } \\
\text { (graduated or not) }\end{array}$} \\
\hline Primary & 265 & 34.3 \\
\hline Secondary & 368 & 47.6 \\
\hline Higher Education & 103 & 13.3 \\
\hline Did not say & 37 & 4.8 \\
\hline \multicolumn{3}{|l|}{ Works away from home? } \\
\hline Yes & 193 & 25.1 \\
\hline No & 576 & 74.9 \\
\hline \multicolumn{3}{|l|}{ First child? } \\
\hline Yes & 341 & 44.2 \\
\hline No & 430 & 55.8 \\
\hline \multicolumn{3}{|l|}{ Type of delivery } \\
\hline Vaginal & 386 & 42.2 \\
\hline Caesarian & 529 & 57.8 \\
\hline
\end{tabular}

The adults accompanying the children less than 120 days old reported that on their first day at home they had been given non-nutritious liquids such as teas (27\%), water, alone $(8 \%)$ or with sugar $(1 \%)$ and milk other than breastmilk (13\%).

Figure 1 demonstrates that consumption of water and teas soon after birth is over $20 \%$. During the first month, teas were more common than water, but, at around 30 days, water was being given to more children than teas were, and consumption declined slowly and uniformly up to 1 year of age, when around $30 \%$ of children were still being given tea (Table 2). At 4 months seven out of every 10 children were drinking water and four out of 10 were 
drinking tea. The third most often consumed liquid was cow's milk, whether powdered or liquid, and which increased consistently as in line with age. Fruits are also introduced into the diet early on, with a significant and constant increase occurring from 3 to 9 months. However, at 12 months there were still children who were not eating fruit. The introduction of soup was identified as being concurrent with the "family meal." Meat and beans have not been included in Figure 1, since their probabilities were practically superimposed over the family meal, indicating that family meals are the principal vehicle for introducing them into the diet.

At 8 months, between 50 and $60 \%$ of the children were consuming soup and the family meal (Figure 1 and Table 3).

There was no difference between the characteristics of mothers who introduced water and teas before 4 months and those who didn't in the majority of parameters (Table 2 ). The only exception was a significant difference in the liquids given on the first day at home. The chance of children being given liquids on the day of interview was greater among those who had consumed them on the day they were discharged from the maternity unit. Those who were given teas on their first day at home were twice as likely to be drinking tea on the day of interview (OR $=1.89$ ), and those given water the day they were discharged from the maternity unit were around 5 times more likely to be receiving teas $(O R=4.76)$ or water $(O R=4.87)$ during their first 4 months. Those given milk on their first day at home were 3 times more likely $(O R=3.31)$ to be receiving milk at the time of interview.
There were no differences between mothers who had not yet introduced solid or semi-solid foods by the recommended age and those who had, with the exception of the introduction of soup, where it was observed that adolescent mothers were more likely $(O R=2.64)$ not to offer this preparation. Mothers with primary or secondary education had a 4.3 times greater risk of not giving their children meat and primaparous mothers had almost 5 times ( $O R=4.9$ ) greater chance of not feeding their children beans by 8 months, although neither of these results attained statistical significance (Table 3 ).

\section{Discussion}

This research project included several precautions taken to guarantee the reliability of its results. One of these was that data collection was standardized by training interviewers and fieldwork supervisors, thus achieving a uniform method of approaching candidates in the vaccination line and of applying the questionnaire with mothers.

The vaccination program coverage on the first day of the 2004 Vaccination Campaign was relatively high in Cuiabá $(89.8 \%)$, being close to that found in a study by Venâncio et al., 10 in which mean coverage in 84 municipalities in São Paulo state was $91.3 \%$. The selection process ensured that every child who presented on vaccination day had an equal chance of taking part in the study. The design effect was close to 1 at all times, i.e. the precision of the results is comparable with that that would have been obtained from a sample of the same size
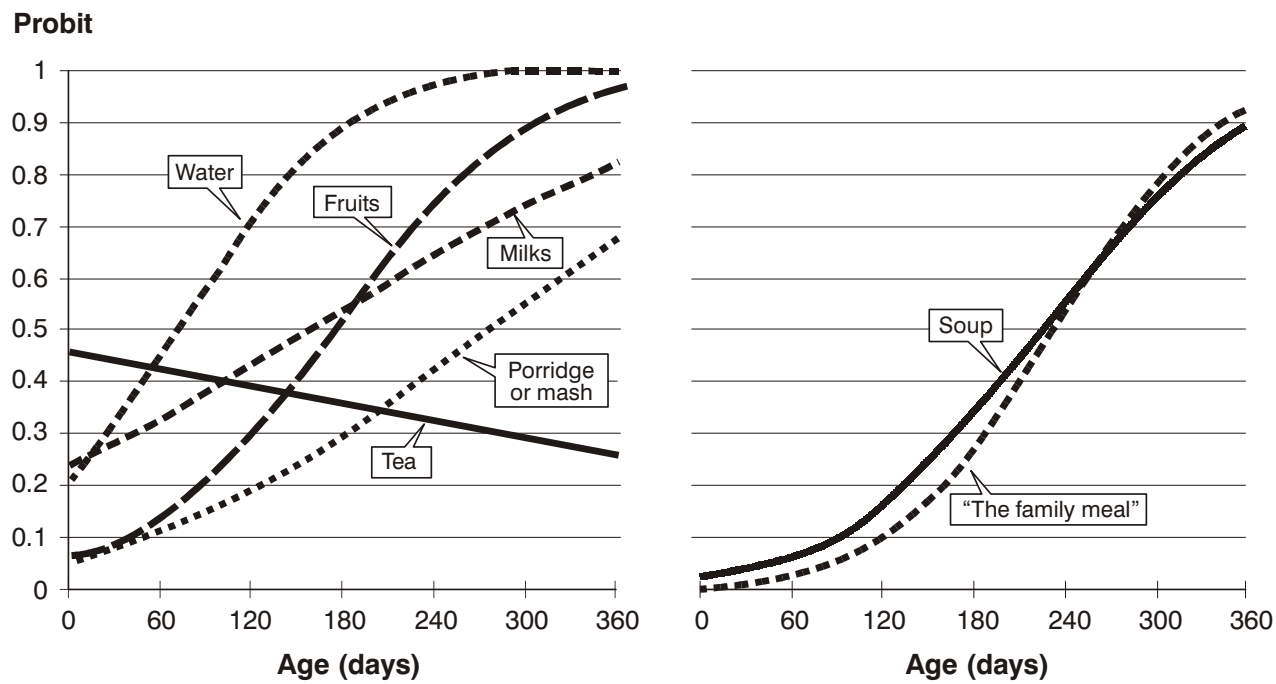

Figure 1 - Distribution graph of probits for different foods by age 
Table 2 - Raw and adjusted estimated odds ratios with their respective confidence intervals for consumption of water, tea, and other types of by children younger than 120 days

\begin{tabular}{|c|c|c|c|c|c|c|c|c|c|c|c|c|}
\hline \multirow{3}{*}{ Variables } & \multicolumn{12}{|c|}{ Current consumption by children aged $<120$ days } \\
\hline & \multicolumn{4}{|c|}{ Teas } & \multicolumn{4}{|c|}{ Water (pure or with sugar) } & \multicolumn{4}{|c|}{ Other types of milk } \\
\hline & Yes & ROR & AOR & $95 \% I C$ & Yes & ROR & AOR & $95 \% I C$ & Yes & ROR & AOR & $95 \% I C$ \\
\hline \multicolumn{13}{|l|}{ 1st day home } \\
\hline \multicolumn{13}{|l|}{ Tea } \\
\hline No & 70 & 1.00 & 1.00 & & 90 & 1.00 & 1.00 & & 51 & 1.00 & 1.00 & \\
\hline Yes & 48 & 2.96 & 1.90 & $1.03-3.49$ & 42 & 1.42 & 0.99 & $0.52-1.88$ & 31 & 1.87 & 1.27 & $0.66-2.45$ \\
\hline \multicolumn{13}{|l|}{ Water } \\
\hline No & 100 & 1.00 & 1.00 & & 114 & 1.00 & 1.00 & & 71 & 1.00 & 1.00 & \\
\hline Yes & 18 & 5.94 & 4.76 & $1.59-14.26$ & 18 & 4.83 & 4.87 & $1.53-15.57$ & 11 & 2.48 & 1.93 & $0.71-5.26$ \\
\hline \multicolumn{13}{|c|}{ Other types of milk } \\
\hline No & 98 & 1.00 & 1.00 & & 112 & 1.00 & 1.00 & & 62 & 1.00 & 1.00 & \\
\hline Yes & 20 & 1.95 & 1.44 & $0.64-3.26$ & 20 & 1.57 & 1.97 & $0.82-4.72$ & 20 & 3.77 & 3.31 & $1.46-7.47$ \\
\hline \multicolumn{13}{|c|}{ Maternal characteristics } \\
\hline \multicolumn{13}{|c|}{ Age (years) } \\
\hline$\geq 20$ & 91 & 1.00 & 1.00 & & 97 & 1.00 & 1.00 & & 63 & 1.00 & 1.00 & \\
\hline$<20$ & 16 & 0.87 & 0.85 & $0.41-1.77$ & 26 & 1.91 & 1.80 & $0.87-3.72$ & 13 & 1.05 & 1.12 & $0.52-2.42$ \\
\hline \multicolumn{13}{|l|}{ Delivery } \\
\hline Vaginal & 52 & 1.00 & 1.00 & & 69 & 1.00 & 1.00 & & 35 & 1.00 & 1.00 & \\
\hline Caesarian & 69 & 1.22 & 1.12 & $0.65-1.94$ & 64 & 0.63 & 0.54 & $0.31-0.95$ & 49 & 1.27 & 1.05 & $0.58-1.91$ \\
\hline \multicolumn{13}{|c|}{ Mother employed } \\
\hline Yes & 22 & 1.00 & 1.00 & & 19 & 1.00 & 1.00 & & 17 & 1.00 & 1.00 & \\
\hline No & 85 & 0.56 & 0.53 & $0.26-1.07$ & 104 & 1.05 & 0.90 & $0.43-1.88$ & 59 & 0.51 & 0.51 & $0.24-1.05$ \\
\hline
\end{tabular}

Multivariate logistic regression model, adjusted for age of child (in days).

$95 \% \mathrm{Cl}=95 \%$ confidence interval; AOR = adjusted odds ratio (multivariate analysis); ROR = raw odds ratio (univariate analysis).

Table 3 - Raw and adjusted estimated odds ratios with their respective confidence intervals for not feeding children soup, the family meal, meat or beans to children $\geq 240$ days old

\begin{tabular}{|c|c|c|c|c|c|c|c|c|c|c|c|c|c|c|c|c|}
\hline \multirow{3}{*}{ Variables } & \multicolumn{16}{|c|}{ Children aged $\geq 240$ days not currently eating } \\
\hline & \multicolumn{4}{|c|}{ Family meal } & \multicolumn{4}{|c|}{ Soups } & \multicolumn{4}{|c|}{ Meat } & \multicolumn{4}{|c|}{ Beans } \\
\hline & No & ROR & AOR & 95\%IC & No & ROR & AOR & 95\%IC & No & ROR & AOR & 95\%IC & No & ROR & AOR & 95\%IC \\
\hline \multicolumn{17}{|l|}{ Age (years) } \\
\hline$\geq 20$ & 45 & 1.00 & 1.00 & & 57 & 1.00 & 1.00 & & 36 & 1.00 & 1.00 & & 8 & 1.00 & 1.00 & \\
\hline$<20$ & 8 & 0.90 & 0.99 & $0.39-2.50$ & 21 & 2.80 & 2.64 & $1.24-5.63$ & 11 & 1.92 & 1.45 & $0.60-3.48$ & 2 & 1.28 & 1.09 & $0.19-6.33$ \\
\hline \multicolumn{17}{|l|}{ Education } \\
\hline \multicolumn{17}{|l|}{ Higher } \\
\hline education & 10 & 1.00 & 1.00 & & 8 & 1.00 & 1.00 & & 2 & 1.00 & 1.00 & & 3 & 1.00 & 1.00 & \\
\hline School & 42 & 0.70 & 0.68 & $0.28-1.65$ & 68 & 1.77 & 1.34 & $0.55-3.25$ & 44 & 4.96 & 4.32 & $0.97-9.34$ & 7 & 0.36 & 0.42 & $0.09-2.01$ \\
\hline \multicolumn{17}{|l|}{ First child? } \\
\hline No & 29 & 1.00 & 1.00 & & 36 & 1.00 & 1.00 & & 22 & 1.00 & 1.00 & & 2 & 1.00 & 1.00 & \\
\hline Yes & 24 & 0.90 & 0.89 & $0.46-1.74$ & 42 & 1.46 & 1.13 & $0.62-2.05$ & 25 & 1.36 & 1.24 & $0.61-2.54$ & 8 & 4.69 & 4.86 & $0.94-24.99$ \\
\hline \multicolumn{17}{|l|}{$\begin{array}{l}\text { Mother } \\
\text { employed? }\end{array}$} \\
\hline Yes & 14 & 1.00 & 1.00 & & 23 & 1.00 & 1.00 & & 13 & 1.00 & 1.00 & & 5 & 1.00 & 1.00 & \\
\hline No & 38 & 1.42 & 1.42 & $0.69-2.92$ & 55 & 1.26 & 1.12 & $0.60-2.10$ & 34 & 1.42 & 1.14 & $0.54-2.41$ & 5 & 0.50 & 0.47 & $0.12-1.84$ \\
\hline
\end{tabular}


obtained by a simple casual process. All of these factors contributed to the quality of the results presented here.

With reference to the "Feeding Guide for Children Under Two Years Old,"1 it is apparent that at least four of the 10 steps to a healthy diet are not being taken by a significant proportion of the population. The first step is to give only breastmilk up until 6 months, with no water, teas or any other foods (step 1). In this study, other foods were found to be introduced very early on with great frequency, from the first day at home onwards, especially water and tea; probably as a result of the belief in Mato Grosso that it is necessary to give extra liquids because of the very hot climate.

Several different studies in Brazil have identified early introduction of complementary foods, ${ }^{11}$ confirming that, at 6 months, when they should only just be starting complementary feeding, a large number of children already consume a variety of foods.

In this study, whether children were given any liquid other than breastmilk on their first day at home was a good predictor of whether they would be given such liquids during their first 4 months of life. It is known that early introduction of liquids and solids is unnecessary and reduces the duration and frequency of breastfeeding, 5,12 interfere with the absorption of important nutrients such as iron, ${ }^{13}$ reduce the efficiency of lactation to retard the next pregnancy ${ }^{14}$ and increase infant morbidity and mortality. ${ }^{4}$ Early exposure to proteins other than those found in human milk is associated with increased risk of diabetes mellitus type I 15 and atopic diseases such as asthma, the effects of which appear to last at least until the child is 10 years old, and other types of allergy. 16,17 certain foods are considered especially allergenic, such as eggs, nuts and oil seeds, and cow's milk, this last being responsible for $20 \%$ of food allergies and is not recommended before 9 to 12 months. ${ }^{15,16}$

The second step in the Feeding Guide recommends that from 6 months on other foods should be slowly and gradually introduced, maintaining breastmilk in the diet until two years of age or more, since from this age onwards the nutritional requirements of infants may no longer be met by human milk alone. ${ }^{8}$ Complementary foods should have a minimum density of $70 \mathrm{kcal} / 100 \mathrm{~mL},{ }^{1}$ which is difficult to achieve with preparations that contain a large percentage of water, such as fruit juice, soups and watery porridges.

The third and fifth steps of the Guide also deal with nutrition after 6 months and recommend that complementary foods (cereals, tubers, meat, fruit and vegetables) be given three times a day (step 3 ) and that complementary foods should be thick from the onset and should be given with a spoon; beginning with pasty foods (mashes/purées) and, gradually, increase the consistency until the child is eating family meals (step 5). Therefore, by 8 months, the majority of children should already have passed through this phase of transition to family meals. In fact, however, it was observed that less than $60 \%$ of them were eating these foods at that age. Although the probabilities of "soup" and "family meal" consumption were similar, (Figure 1) at 8 months children begin to consume less soup and eat more family meals. These, being more solid, have greater nutritional density, i.e. a larger amount of nutrients per volume or weight of food. ${ }^{1}$

The fact that adolescent mothers gave their children less soup than adult mothers did may be related to its preparation, made especially for the child. There is no consensus on the differences between the diets of adolescent and adult mothers' children. Vieira et al. ${ }^{18}$ found that the complementary feeding of the children of adolescents was similar to that of adult mothers' children, except for lower intake of meat and greater intake of eggs, since adolescents also have lower purchasing power to be able to buy meat. In contrast, Carruth et al. ${ }^{19}$ observed that the children of adolescent mothers ate more fat, began to eat with their own hands earlier and ate cereals earlier than the children of adult mothers, without, however, differing in terms of the intake of meat, fruit and vegetables.

There was a tendency, although not a significant one, to an association between two maternal characteristics and the feeding practices of their children. Lower level of education, which probably operates as an indirect indicator of socioeconomic status, is associated with a 4 times greater chance of the child not eating meat, a food that is much more expensive than beans are, the other protein source that was investigated. The association between not feeding a child beans and that child being its mother's first may be an expression of excess zeal among primaparous mothers, who avoid giving their first child food that has certain taboos linked to it, as being "rich" or "heavy."

This study is limited by the fact that it did not identify food groups, but intake of foods typically prepared for infants (mashes/porridge, soups, fruit, etc), preventing the intake of important nutrients such as iron and vitamin $C$ from being investigated. Nevertheless, it appears that fruit has a prominent role in the diet of the population of Cuiabá and, after water, it is the food that is most often added to infants' diets. However, it is likely that fruit is not being eaten in sufficient quantities, nor together with meals, since there is a high anemia prevalence among children under the age of three in the region. 20

The results found here demonstrate the importance of publicizing the harm done by early introduction of foods, in particular non-nutritional liquids such as water and tea, and other types of milk. This education should be emphasized during prenatal care and at discharge from the maternity unit, since mothers who give these liquids to their children on the first day home have a greater chance of also doing so later, with all the effects that this 
early introduction implies. Care should also be taken with the introduction of the family's meals to the infant's diet, feeding transition foods from 6 to 8 months when the infant should be partaking of the whole family meal.

\section{Acknowledgements}

Thanks are due to the Instituto de Saúde de São Paulo, for work on the study design and follow-up, to the State and Municipal Health Departments for permission to carry out the research and for funding, to the academic staff at the Nutrition, Medicine and Nursing Faculties of the Universidade Federal de Mato Grosso, for their help with data collection and to those who took part as fieldwork supervisors, to CAPES and CNPq for bursaries granted for Masters degrees and Scientific Initiative.

\section{References}

1. Brasil, Ministério da Saúde. Guia alimentar para crianças menores de 2 anos. Brasília: Ministério da Saúde; 2005.

2. Monte $C M G$, Giugliani ERJ. Recomendações para alimentação complementar da criança em aleitamento materno. J Pediatr (Rio J). 2004;80:S131-41.

3. Kramer MS, Kakuma R. The optimal duration of exclusive breastfeeding: a systematic review. Geneva: WHO; 2002.

4. Victora CG, Vaughan JP, Lombardi C, Fuchs SMC, Gigante LP, Smith PG, et al. Evidence for protection by breast-feeding against infant deaths from infectious diseases in Brazil. Lancet. $1987 ; 2: 317-22$.

5. Organização Mundial da Saúde. Evidências científicas dos dez passos para o sucesso no aleitamento materno. Brasília: OPAS/ OMS; 2001.

6. Instituto Brasileiro de Geografia e Estatística. Resultados do Universo relativo às características da população dos domicílios $\mathrm{n}^{\circ} 26 ; 1992$.

7. Instituto Brasileiro de Geografia e Estatística. Censo demográfico. http://www.sidra.ibge.gov.br. Access: 20/06/2005. (Censo 2000: tabela 1518, município Cuiabá).

8. World Health Organization, United Nations Children's Fund (UNICEF). Complementary feeding of young children in developing countries: a review of current scientific knowledge. Geneva: WHO; 1998.
9. Finney DJ. Probit analysis. $3^{a}$ ed. Cambridge: Cambridge University Press; 1980.

10. Venâncio SI, Escuder MML, Kitoko $P$, Rea MF, Monteiro CA. Freqüência e determinantes do aleitamento materno em municípios do Estado de São Paulo. Rev Saude Publica. 2002;36:313-8.

11. Oliveira LPM, Assis AMO, Pinheiro SMC, Prado MS, Barreto ML. Alimentação complementar nos primeiros dois anos de vida. Rev Nutr. 2005;18:459-69.

12. Ashraf RN, Jalil F, Aperia A, Lindblad BS. Additional water is not needed for healthy breast-fed babies in a hot climate. Acta Paediatr. 1993;82:1007-11.

13. Abrams AS, Wen J, Stuff JF. Absorption of calcium, zinc and iron from breast-milk by five to seven-month-old infants. Pediatr Res. 1997;41:384-90.

14. Dewey KG, Cohen RJ, Rivera LL, Canahuati J, Brown KH. Effects of age at introduction of complementary foods to breast-fed infants on duration of lactational amenorrhea in Honduran women. Am J Clin Nutr 1997;65:1403-9.

15. Gerstein HC. Cow's milk exposure ant type I diabetes mellitus. A critical overview of the clinical literature. Diabetes Care. 1994;17:13-9.

16. Arshad SH. Food allergen avoidance in primary prevention of food allergy. Allergy. 2001;56:113-6.

17. Van Odjik J, Kull I, Borres MP, Brandtzaeg P, Edberg U, Hanson LA, et al. Breastfeeding and allergic disease: a multidisciplinary review of the literature (1966-2001) on the mode of early feeding and its impact on later atopic manifestations. Allergy. 2003;58:833-43.

18. Vieira MLF, Silva JLCP, Barros-Filho AA. A amamentação e a alimentação complementar de filhos de mães adolescentes são diferentes das de filhos de mães adultas? J Pediatr (Rio J). 2003;79:317-24.

19. Carruth BR, Nevling W, Skinner JD. Developmental and food profiles of infants born to adolescent and adult mothers. J Adolesc Health. 1997;20:434-41.

20. Brunken GS, Guimarães LV, Fisberg M. Anemia em crianças menores de 3 anos que freqüentam creches públicas em período integral. J Pediatr (Rio J). 2002;78:50-6.

Correspondence:

Gisela Soares Brunken

Campus UFMT

Av. Fernando Correa da Costa, s/no

CCBS III, térreo, Instituto de Saúde Coletiva

CEP 78060-900 - Cuiabá, MT - Brazil

Tel.: + 55 (65) 3615.8260, +55 (65) 3627.2664

Fax: +55 (65) 3615.8267

E-mail: brunken@terra.com.br 